\title{
Learning Aids and Japanese Teaching
}

\author{
Dongkun Hao ${ }^{\mathrm{a}}$, Zhan Liu ${ }^{\mathrm{b}}$, Changming Xie ${ }^{\mathrm{c}}$, Mengyun Zou ${ }^{\mathrm{d}}$ and Xue Gonge, * \\ School of Foreign Languages and International Education, Dalian Ocean University, Dalian \\ 116000, China

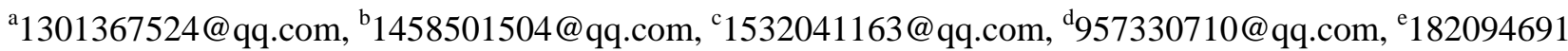 \\ @qq.com \\ *Corresponding author: 182094691@qq.com
}

Keywords: Learning aids, Japanese teaching, language learning

\begin{abstract}
Cards and other means are used to assist teaching in traditional foreign language teaching. However, with the rapid development of science and technology, the teaching efficiency of such learning aids is low and cannot be suitable for modern teaching. In particular, the 50 picture cards used in Japanese teaching are relatively rigid and cannot play a role in deepening memory. In view of this, this study intends to design a Japanese language learning aid device, on the one hand, to increase the entertainment and interaction of Japanese language learning, on the other hand, strengthen the learning and memory of Japanese Hiragana, katakana and pronunciation, and improve the efficiency of Japanese learning.
\end{abstract}

\section{Pros and cons of modern learning aids}

With the development of society and the advancement of science and technology, although the learning aids in traditional teaching can still play a certain role in teaching, it can no longer adapt to modern teaching. Especially with the development of the Internet, modern technologies such as mobile phones and computers Products are gradually used in teaching, which not only improves the efficiency of "teaching", but also promotes the effect of "learning".

For example, a foreign language learning website not only has a large amount of learning resources, but also learners can learn autonomously at any time and place. In addition, it can meet the learning of foreign language learners at different stages and levels from elementary to advanced levels. Moreover, there is no limit to languages and categories, covering all aspects from simple letters and intonation to high difficulty in listening, speaking, reading and writing. It can be said that foreign language learning website has the characteristics of specialization and systematization, and it is a good helper for foreign language learners to learn foreign languages.

As another example, the popularity of mobile phones has greatly facilitated people's lives. Using mobile phones to assist teaching in teaching, such as learning apps, flipping classrooms, Mobile phone check-in, etc., can be implemented on mobile phones. It can be said that mobile phones are a modern learning Means can play a role in improving learning effects.

However, no matter which modern learning method is based on the network, it cannot be achieved without the "support" of the network. Moreover, there are many and complex contents of 
network resources, sometimes there are errors, which are different from the carefully prepared contents of teachers. In addition, students who watch electronic devices such as mobile phones and computers for a long time may not concentrate on the one hand; on the other hand, if they choose resources that are not suitable for them or have the wrong results, the consequences can be imagined. Therefore. The author considers designing a more traditional Japanese learning aid device that is different from relying entirely on the Internet. This device can increase the entertainment and interaction of Japanese learning on the one hand; on the other hand, it strengthens the Japanese hiragana, katakana and pronunciation Learn and memorize and improve the efficiency of Japanese learning.

\section{Japanese language learning aids}

\subsection{The basic structure of learning aids}

Learning assistance device, as the name suggests, is a device that helps learning. The device is designed for the study of hiragana and katakana in Japanese fifty tone picture.

\subsubsection{Production of learning aids}

There are seventy-one pseudonyms in Japanese, including unvoiced, dull, semi-voiced and dial. There are five basic vowels, forty-one consonants, and four cannot be spelled. Kana representing forty-five unvoiced syllables, according to the pronunciation rules can be arranged into a list, this kana table is called fifty tone pictures. It is designed as a Japanese language learning aid device, including a desk, control panel, speakers, cards, and text tooth pads. A control panel is arranged below the card slot, and a number of through holes are set in the card slot, each through hole corresponds to a contact on the control panel, the control panel is electrically connected to the speaker, and the control panel is connected to the power supply, and the front of the card is set There is text, and a boss is set on the reverse side of the card, and the speaker sounds when the contacts are in contact with the boss; the dial surface of the text tooth disk is provided with text, and the middle part of the text tooth disk is rotatably connected with a rotating shaft, and the rotating shaft is set on the desk of the desk The sprocket is three adjacent text sprockets that can be meshed.

\subsubsection{Operation of learning aids}

The cards include katakana cards, hiragana cards, and pronunciation cards. Fifty katakana cards are randomly set on the katakana card, and one katakana is set for each of the katakana cards; fifty hiragana as are randomly set on the hiragana card, one hiragana is set for each of the hiragana cards; fifty Roman phonetic symbols are randomly set on the pronunciation card, and one roman phonetic symbol is set for each of the pronunciation cards, and each of the roman phonetic alphabet on the pronunciation card corresponds to one of the katakana and one of the hiragana. The left and right sides of the card reading slot are provided with fifty through holes, and the left side of card reading slot is kana card reading area, the right side of the card reading slot is the hiragana card reading area, each of the through holes corresponds to a boss of the card, and the control panel corresponds to each of the through holes A contact is provided, and each contact with the card corresponds to the pronunciation of the katakana card or the hiragana card.

\subsection{The main learning mode of learning aids}

This learning aid is divided into three learning modes: teaching mode, self-study mode, and pronunciation learning mode. 


\subsubsection{Teaching mode}

Compared with the prior art blackboard or card teaching mode, the teaching efficiency is lower and cannot be applied to modern teaching. This auxiliary learning device adopts multimedia teaching. The device is controlled by operating the control panel. With professional pronunciation, it can Diversified teaching is in line with modern education concepts.

\subsubsection{Self-study mode}

The traditional teaching mode makes it difficult for learners to learn by themselves, and it is difficult to find and correct learning mistakes. This learning aid is easy to operate with pronunciation, allowing learners to self-learn and review, which can better consolidate their knowledge.

\subsubsection{Pronunciation learning mode}

The most important point of language learning is the formation of the language environment. Many learners learn what we call "dumb" Japanese, that is, they can only "listen" and "write" but not read. This learning aid while learning hiragana and katakana, there will also be standard pronunciations, so that learners can adapt to the environment of the language used while learning syllables, enhance memory and improve efficiency while also practicing pronunciation.

These three modes are very helpful for learners. At the same time, they can help learners develop good learning habits and improve learning efficiency.

\subsection{The characteristics of learning aids}

The first is the practical features. This learning aid is simple, fast, and easy to understand. It is suitable for all ages and makes people easily and happily integrate into language learning, deepening the memory and understanding of the fifty-sound chart, and improving learning efficiency. You can also experience the fun of this learning aid during the operation and add fun. At the same time, during recording, you can find out the standard of your pronunciation, strengthen the practice of listening and speaking, and enhance the language. Learning efficiency.

Second is the teaching function. Compared with the traditional teaching mode, this learning aid is more free, convenient, fast and efficient. For example, children can also learn at home without the guidance of the teacher and the parent's company. At the same time, for students who are new to Japanese, you can also use this learning aid to quickly get started, avoiding the problem of rote memorization of the fifty-sounding map and giving up learning of Japanese, and increase interest in learning Japanese. In addition, learning assistance. The device can unified the problem of non-standard pronunciation and improve the Japanese learning ability. Students can learn at a time suitable for them, or adjust the learning progress according to their own learning ability, avoiding the problem of openness in traditional teaching, which greatly improves Learning efficiency.

\section{Application and debugging of learning aids}

\subsection{The advantages of learning aids}

First of all, it is real and intuitive, with interaction and fun. The learning aids are real and intuitive, with strong interaction and fun. Compared with the traditional teaching mode, the Japanese learning aids have an intuitive touch to enhance Remembrance, not rigid typeface memory. 
Through direct touch, it produces tactile sensations, and at the same time, the sounds produced can stimulate learners to learn the fifty tone chart in the senses of listening and reading. The clear pronunciation can align the card with the card slot, and the auxiliary device can respond in time, enhancing the interaction in learning. As we all know, language learning is extremely boring. When using the auxiliary device to learn, it is like a card game. Increasing the fun in language learning.

Secondly, it can improve the autonomous learning ability. Learning assistance devices can improve the autonomous learning ability of students. Everyone is a different individual, so the learning ability and acceptance ability are also different, so everyone's progress in learning will be different. When using learning aids, students can adjust the speed and state of learning according to their own abilities, and they can also repeat learning or review without remembering the knowledge points. In the new era, students' learning methods are not limited to one classroom. Many language beginners are ashamed to ask their teachers questions during the learning process. When using assisted learning devices, students can learn again without understanding. Secondary learning, in this way, can improve students' awareness of autonomous learning and enhance their ability to learn autonomously.

\subsection{Deficiencies in learning aids}

First of all, students have high requirements for self-discipline ability. Learning with the aid of learning devices has higher requirements for students 'self-discipline ability. In practical applications, there is a lack of teacher management and supervision, so students' self-discipline ability has become a learning aid important factors when installing devices. If students are not self-disciplined, auxiliary devices may be left aside, resulting in a waste of resources.

Secondly, there are too few functions to support the systematic learning of the language. At present, the Japanese learning aids only support the study of the syllabary (including Hiragana, Katakana, etc.), and cannot systematically learn Japanese. In learning any language. At the beginning, you need to learn simple Pinyin, letters, kana, etc., but the language learning is not limited to this. To learn a language systematically, we also need to learn the words, sentences, grammar, expressions. In particular, listening, speaking, reading and writing, fluent communication with others is the master of a language. Therefore, the function of the Japanese learning aids is not enough to support the learning of the entire language.

Finally, the lack of human touch is not conducive to emotional communication. For people, emotional communication is very important, but human-computer interaction is lack of communication, which is not conducive to language learning. In the process of language learning, teachers are a An indispensable role. Learning languages is for communication. We have always believed that when learning languages, students are better accepted by the language when they are in a good language learning environment. If the language is being learned. The lack of communication will reduce the efficiency of language learning and is not conducive to communication between people.

\section{Application of learning aids in Japanese teaching}

\subsection{Deficiencies of traditional teaching models}

First of all, the teaching mode is monotonous. In traditional Japanese teaching, classes are usually taught in units of classes. The teacher will teach the content of the lesson to the entire class according to the teaching plan and syllabus. The traditional teaching is based on the teacher's teaching. Students are in a state of passive learning, and it is unclear whether the students have truly mastered the content of the curriculum and whether they have been transformed into their own 
knowledge. In addition, traditional teaching is difficult to mobilize the enthusiasm of students to learn, which is not conducive to divergent thinking.

Secondly, it is not conducive to the development of students 'personality. In the traditional teaching mode, teachers can easily ignore individual learning and cannot teach students based on their aptitude. This method is not conducive to training students' independent and autonomous learning ability.

\subsection{The advantages of using Japanese teaching aids}

In the case of using a Japanese learning aid, the learner is taught by the aid. The learner's communication object is the learning aid, and the student's communication object is a physical tool. Therefore, the learner uses the learning aid. This kind of teaching mode embodies the "human-computer interaction" teaching method. In the teaching using Japanese learning aids, learners can find learning methods suitable for them through the learning aids, which is more conducive to the personality development of students. Helps develop students' autonomous learning ability.

In a nutshell, using the characteristics of learning aids, such as convenience, strong operability and efficient interaction, has greatly solved the difficulties in learning Japanese memory. It can be used as a complementary tool for traditional Japanese teaching, and it is used for Japanese teaching Has a promoting effect.

\section{Acknowledgments}

This work was financially supported by Innovation and entrepreneurship training program for college students in Dalian Ocean University in 2019 fund (201910158059).

\section{References}

[1] Chen Zhenzhen, Jia Jiyou, Twenty Years of Research on Mobile Assisted Language Learning in China: Review and Prospect, Foreign Languages, No. 1 of 2020.

[2] Lu Yingbo, Yun Ping. Research on Foreign Language Teaching Model Based on Mobile Learning Terminal. Modern Educational Technology, 2013. 